Correction

\title{
Correction: Zhao, H., et al. Automatic Estimation of Crop Disease Severity Levels Based on Vegetation Index Normalization. Remote Sensing 2020, 12, 1930
}

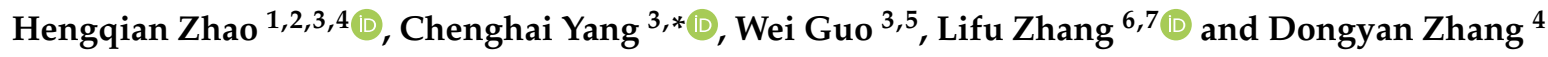 \\ 1 College of Geoscience and Surveying Engineering, China University of Mining and Technology, \\ Beijing 100083, China; zhaohq@cumtb.edu.cn \\ 2 State Key Laboratory of Coal Resources and Safe Mining, China University of Mining and Technology, \\ Beijing 100083, China \\ 3 United States Department of Agriculture-Agricultural Research Service, Aerial Application Technology \\ Research Unit, College Station, TX 77845, USA; guoweiworkhome@126.com \\ 4 Anhui Engineering Laboratory of Agro-Ecological Big Data, Anhui University, Hefei 230601, Anhui, China; \\ hello-lion@hotmail.com \\ 5 College of Information and Management Science, Henan Agricultural University, \\ Zhengzhou 450002, Henan, China \\ 6 Key Laboratory of Oasis Eco Agriculture, Xinjiang Production and Construction Group, Shihezi University, \\ Shihezi 832003, Xinjiang, China; zhanglf@radi.ac.cn \\ 7 Institute of Remote Sensing and Digital Earth, Chinese Academy of Sciences, Beijing 100101, China \\ * Correspondence: chenghai.yang@usda.gov; Tel.: +1-979-571-5811
}

The authors wish to make the following correction to this paper [1]. Formula (1)

$$
X_{\text {norm }}=\frac{X-X_{\min }}{X_{\max }-X_{\min }}
$$

should be replaced with

$$
X_{\text {norm }}=\frac{X_{\max }-X}{X_{\max }-X_{\min }}
$$

The authors would like to apologize for any inconvenience caused to the readers by these changes.

\section{References}

1. Zhao, H.; Yang, C.; Guo, W.; Zhang, L.; Zhang, D. Automatic estimation of crop disease severity levels based on vegetation index normalization. Remote Sens. 2020, 12, 1930. [CrossRef]

Publisher's Note: MDPI stays neutral with regard to jurisdictional claims in published maps and institutional affiliations.

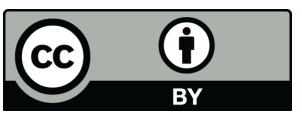

(C) 2020 by the authors. Licensee MDPI, Basel, Switzerland. This article is an open access article distributed under the terms and conditions of the Creative Commons Attribution (CC BY) license (http://creativecommons.org/licenses/by/4.0/). 